\title{
Preventive effects of tyrosol, a natural phenolic compound, on anterior uveitis induced by anterior chamber paracentesis in healthy beagle dogs
}

\author{
Kazuaki SATO ${ }^{1)}$, Kazutaka KANAI ${ }^{1) *}$, Maiko OZAKI ${ }^{1)}$, Takaaki KAGAWA ${ }^{1)}$, \\ Mizuki KITA ${ }^{1)}$, Yohei YAMASHITA ${ }^{1)}$, Noriaki NAGAI') and Kazuki TAJIMA ${ }^{1)}$ \\ 1)Department of Small Animal Internal Medicine II, School of Veterinary Medicine, Kitasato University, \\ Towada, Aomori 034-8628, Japan \\ 2) Faculty of Pharmacy, Kindai University, Higashi-Osaka, Osaka 577-8502, Japan
}

J. Vet. Med. Sci.

81(4): 573-576, 2019

doi: $10.1292 / j v m s .18-0723$

Received: 7 December 2018 Accepted: 14 February 2019 Published online in J-STAGE: 25 February 2019
ABSTRACT. We investigated the effects of tyrosol (Tyr) on anterior chamber paracentesis $(A C P)$-induced anterior uveitis in beagle dogs, as determined by protein and prostaglandin E2 (PGE2) concentrations in the aqueous humor (AH). Tyr at a dose of 100 or $200 \mathrm{mg} / \mathrm{kg}$ or $2.2 \mathrm{mg} /$ $\mathrm{kg}$ of carprofen as a positive control was administered orally twice daily from 2.5 days before paracentesis. The initial ACP was performed in one eye of individual dogs and $0.5 \mathrm{~m} / \mathrm{AH}$ was aspirated. The secondary AH was collected 60 min later. Pretreatment with $200 \mathrm{mg} / \mathrm{kg}$ of Tyr and carprofen significantly decreased aqueous protein and PGE2 concentrations compared to the control group. Overall, these findings suggested that Tyr was useful for the management of canine anterior uveitis.

KEY WORDS: anterior chamber paracentesis, anterior uveitis, blood-aqueous barrier, dog, tyrosol

Anterior uveitis is a common ophthalmic disease in veterinary ophthalmology that can cause varying degrees of ocular discomfort and can threaten vision in severe cases [19]. This disease causes breakdown of the blood-aqueous barrier (BAB), which allows plasma proteins and cells into the aqueous humor $(\mathrm{AH})[8,19]$. Many etiologies exist for anterior uveitis, such as infectious, neoplastic, immune-mediated, or idiopathic causes [19]. Surgical procedures, including intraocular surgery and anterior chamber paracentesis (ACP), can also collapse the anterior chamber, resulting in BAB disruption. Therefore, ACP has been used as a model of anterior uveitis in a various species $[4,22,30]$. The inflammatory response in the ACP-induced uveitis model is primarily via prostaglandin E2 (PGE2) production [20, 32].

Tyrosol [Tyr; 2-(4-hydroxyphenyl) ethanol], a phenolic compound abundant in extra virgin olive oil, wine, and other plant extracts, exhibits many biologic activities, such as anti-inflammatory [2], anticancer [12], antidiabetic [6], and neuro- [5] and cardio-protective [26] properties. Anti-inflammatory effects and molecular mechanisms of Tyr were previously evaluated on endotoxin-induced uveitis in rats [29]. In this study, we investigated the effect of Tyr on ACP-induced anterior uveitis in dogs, and compared its efficacy to that of carprofen, a prostaglandin (PG) synthetase inhibitor used for dogs, and sometimes cats.

A total of 20 clinically normal beagle dogs of either sex, between 4 and 6 years old and weighing between 8.5 and $11.7 \mathrm{~kg}$, were obtained from the Institution for Animal Reproduction (Ibaraki, Japan). All dogs were confirmed with no ocular abnormalities as determined by ophthalmic examination before the experiment, including anterior segment biomicroscopy, indirect ophthalmoscopy, Schirmer's tear test, fluorescein staining, and intraocular pressure measurement with applanation tonometry. After the experiment, each dog routinely received topical $0.1 \%$ dexamethasone (Santeson ${ }^{\circledR}$ ophthalmic solution 0.1\%; Santen Pharmaceutical Co., Ltd., Osaka, Japan) and $0.3 \%$ ofloxacin (Tarivid ${ }^{\circledR}$ ophthalmic solution $0.3 \%$; Santen Pharmaceutical Co., Ltd., Osaka, Japan) three times daily on the operated eyes for 5 days. Study design and animal housing were approved by the President of Kitasato University through judgment by institutional animal care and use committee of Kitasato University; approval number: 18-135.

The dogs were assigned randomly to a control group $(\mathrm{n}=5)$ and three treatment groups (n=5/group). Then, $100 \mathrm{or} 200 \mathrm{mg} / \mathrm{kg}$ of Tyr (Sigma-Aldrich Co., St. Louis, MO, U.S.A.) or $2.2 \mathrm{mg} / \mathrm{kg}$ of carprofen (Rimadyl ${ }^{\circledR}$, Zoetis Japan K.K., Tokyo, Japan) was orally administered in meatballs made of wet dog food twice daily from 2.5 days before paracentesis, with a total of five administrations. The control group dogs received meatballs without the drug according to the same schedule as the treatment group dogs.

*Correspondence to: Kanai, K.: kanai@vmas.kitasato-u.ac.jp

(c2019 The Japanese Society of Veterinary Science 
Table 1. Protein concentrations of the primary and secondary AH in each experimental group

\begin{tabular}{|c|c|c|c|c|}
\hline \multirow[b]{2}{*}{ Group } & \multirow[b]{2}{*}{$\begin{array}{l}\text { Control } \\
(\mathrm{n}=5)\end{array}$} & \multirow[b]{2}{*}{$\begin{array}{l}\text { Carprofen } \\
(\mathrm{n}=5)\end{array}$} & \multicolumn{2}{|c|}{ Tyr } \\
\hline & & & $\begin{array}{c}100 \mathrm{mg} / \mathrm{kg} \\
(\mathrm{n}=5)\end{array}$ & $\begin{array}{c}200 \mathrm{mg} / \mathrm{kg} \\
(\mathrm{n}=5)\end{array}$ \\
\hline Primary AH (mg/d $l)$ & $78.2 \pm 14.4$ & $70.8 \pm 4.0$ & $81.8 \pm 12.9$ & $84.1 \pm 13.3$ \\
\hline Secondary AH $(\mathrm{mg} / \mathrm{d} l)$ & $1,776.9 \pm 249.6^{*}$ & $1,087.9 \pm 180.0^{\mathrm{a}) *}$ & $1,746.2 \pm 228.7^{\mathrm{b}) *}$ & $1,155.4 \pm 187.8^{\mathrm{a}) *}$ \\
\hline
\end{tabular}

All results are presented as mean \pm SD. ${ }^{*}$ Significant $(P<0.001)$ differences between protein concentrations in primary AH and those in secondary $\mathrm{AH}$ in each experimental group. Subscripts a and b represent significant differences between protein concentrations in secondary $\mathrm{AH}$ of the control group and those of carprofen group or Tyr $200 \mathrm{mg} / \mathrm{kg}$ group $(P<0.001)$, and between protein concentrations in secondary AH of carprofen group or Tyr $200 \mathrm{mg} / \mathrm{kg}$ group and those of Tyr $100 \mathrm{mg} / \mathrm{kg}$ group $(P<0.001)$, respectively.

Table 2. PGE2 concentrations of the primary and secondary AH in each experimental group

\begin{tabular}{|c|c|c|c|c|}
\hline \multirow[b]{2}{*}{ Group } & \multirow{2}{*}{$\begin{array}{l}\text { Control } \\
(\mathrm{n}=5)\end{array}$} & \multirow{2}{*}{$\begin{array}{c}\text { Carprofen } \\
(\mathrm{n}=5)\end{array}$} & \multicolumn{2}{|c|}{ Tyr } \\
\hline & & & $\begin{array}{c}100 \mathrm{mg} / \mathrm{kg} \\
(\mathrm{n}=5)\end{array}$ & $\begin{array}{c}200 \mathrm{mg} / \mathrm{kg} \\
(\mathrm{n}=5)\end{array}$ \\
\hline Primary AH $(n g / m l)$ & $0.057 \pm 0.025$ & $0.044 \pm 0.011$ & $0.048 \pm 0.029$ & $0.060 \pm 0.039$ \\
\hline Secondary AH $(n \mathrm{~g} / \mathrm{m} l)$ & $13.36 \pm 3.24 *$ & $6.27 \pm 2.69^{\mathrm{a}) *}$ & $14.49 \pm 5.66^{\mathrm{b}) *}$ & $7.33 \pm 1.52^{\mathrm{a}) *}$ \\
\hline
\end{tabular}

All results are presented as mean $\pm \mathrm{SD}$. ${ }^{*}$ Significant $(P<0.01)$ differences between PGE2 concentrations in primary AH and those in secondary $\mathrm{AH}$ in each experimental group. Subscripts a and b represent significant differences between PGE2 concentrations in secondary $\mathrm{AH}$ of the control group and those of carprofen group or Tyr $200 \mathrm{mg} / \mathrm{kg}$ group $(P<0.05)$, and between PGE2 concentrations in secondary AH of carprofen group or Tyr $200 \mathrm{mg} / \mathrm{kg}$ group and those of Tyr $100 \mathrm{mg} / \mathrm{kg}$ group $(P<0.05)$, respectively.

All dogs undergoing paracentesis were sedated by intravenous administration of a combination of medetomidine (Nihonzenyaku Industry Co., Ltd., Fukushima, Japan), midazolam (Astellas Pharma, Inc., Tokyo, Japan), and butorphanol (Meiji Seika Pharma Co., Ltd., Tokyo, Japan) at doses of $0.01,0.15$, and $0.025 \mathrm{mg} / \mathrm{kg}$, respectively. ACP was performed in one eye determined by coin toss for each dog. Before each paracentesis, the operated eye was irrigated with saline and a 1:16 saline dilution of $10 \%$ povidone-iodine solution, and then, a topical anesthetic was applied to the eye. A 27 gauge needle attached to a tuberculin syringe was inserted into the anterior chamber through the dorsolateral perilimbal cornea, taking care not to disturb the iris, lens, or corneal endothelium. Then, $0.5 \mathrm{ml} \mathrm{AH}$ was withdrawn in a controlled manner to prevent aqueous leakage. Immediately after the first paracentesis, $0.05 \mathrm{mg} / \mathrm{kg}$ of atipamezole hydrochloride (Nihonzenyaku Industry Co., Ltd.) was administered intravenously to reverse the medetomidine effect. At 60 min later, the dogs were sedated again and the secondary AH was collected in the same manner as for the first collection. Following the second ACP, atipamezole hydrochloride was administered again.

AH samples were centrifuged at 3,000 rpm for $5 \mathrm{~min}$ at $4^{\circ} \mathrm{C}$ immediately after collection, and the supernatants were divided for protein and PGE2 concentration measurements. AH protein concentration was measured on the day of sample collection, and samples for PGE2 concentration measurement were stored at $-80^{\circ} \mathrm{C}$ until assayed. AH protein and PGE2 concentrations were determined in duplicates by a bicinchoninic acid protein assay kit (Pierce, Rockford, IL, U.S.A.) and a commercially available enzyme immunoassay kit (Prostaglandin E2 Express ELISA Kit; Cayman Chemical Co., Ann Arbor, MI, U.S.A.), respectively.

All data are presented as means \pm standard deviation. Commercially available software (StatMate III; ATMS Co., Ltd., Tokyo, Japan) was used for statistical analysis. Differences in mean protein and PGE2 levels between the primary and secondary AH in each group were analyzed by a paired Student's $t$-test. Differences in protein and PGE2 concentrations in the primary and secondary AH among the four groups were analyzed by one-way analysis of variance followed by a Newman-Keuls post hoc multiple comparisons test. Significance was set at $P<0.05$ for all analyses.

ACP resulted in significantly increased AH protein concentrations in each group (Table 1), indicating BAB disruption. Mean protein concentrations in the secondary $\mathrm{AH}$ of dogs treated with $100 \mathrm{mg} / \mathrm{kg}$ of Tyr were not significantly different from those of the control group. Conversely, Tyr at a dose of $200 \mathrm{mg} / \mathrm{kg}$ and carprofen significantly reduced BAB breakdown by more than $30 \%$ of protein content elevation in the control group $(P<0.001)$, and there was no significant difference between these treatment groups.

At $60 \mathrm{~min}$ after the first paracentesis, $\mathrm{PGE}_{2}$ concentration significantly increased in each group (Table 2). Also, $100 \mathrm{mg} / \mathrm{kg}$ of Tyr did not significantly influence $\mathrm{PGE}_{2}$ elevation after ACP compared to the control group, whereas Tyr at a dose of $200 \mathrm{mg} / \mathrm{kg}$ and carprofen significantly reduced the elevated $\mathrm{PGE}_{2}$ concentrations by 45 and $53 \%$, respectively $(P<0.05)$. There was no statistically significant differences in this parameter between these treatment groups.

Uveitis can be a debilitating, painful, and vision-threatening disease producing various complications, including glaucoma, cataract, or retinal detachment, which can lead to blindness [24]. Corticosteroids and nonsteroidal anti-inflammatory drugs are used extensively to treat uveitis in human and veterinary medicine $[1,3,11,13]$. Convincing evidence exists that these drugs can reduce uveitis in clinical and experimental studies [22, 31, 33]; however, their long-time use can risk ocular and systemic side effects, such as worsening infection, inhibited corneal wound healing, cataract formation, ocular hypertension, adrenal suppression, hepatopathy, 
gastrointestinal irritation or ulceration, and inhibited platelet function [11, 13]. Therefore, establishment of adjunctive approaches for treatment of uveitis is desirable to decrease the incidence of these side effects.

Recently, natural compounds have received considerable attention for reducing experimentally induced uveitis [15, 17]. We previously demonstrated that Tyr showed significant inhibitory effects on endotoxin-induced uveitis in rats, and its potency was almost equivalent to that of prednisolone [28]. In this study, pretreatment with $200 \mathrm{mg} / \mathrm{kg}$ of Tyr significantly mitigated BAB breakdown and decreased PGE2 production in the secondary AH in dogs. Several factors may stimulate BAB breakdown, including cytokines, neuropeptides, and lipid-derived substances $[7,10,16]$. Of these, PGs are considered important factors in the alteration of BAB stability in clinical cases [23] and experimental uveitis models of several species [20, 21, 30]. In the ACP-induced uveitis model, PGE2 has been shown solely as a mediator mainly causing ocular inflammatory responses [20]. Therefore, the inhibitory effect of Tyr on BAB breakdown may be associated with decreased PGE2 production in the secondary AH.

The limitation of this study is the different pathophysiology of ACP-induced uveitis from that observed in clinical cases. Surgical procedures, including ACP, can induce ocular inflammation as evidenced solely by increased eicosanoid levels in AH $[18,20,25]$, although more mediators have been shown to stimulate BAB disruption in clinical cases of dogs with ocular disorders $[9,14]$. Therefore, the canine uveitis model used in this study may not reproduce real clinical situations. In addition, we could not address the safety and toxicity of Tyr in dogs; to our knowledge, there is only one study with dogs to this effect, and that study demonstrated that oral administration with Tyr at a dose of $10 \mathrm{mg} / \mathrm{kg}$ for 3 months showed no toxicity [27]. Further studies for the assessment of safety and potential toxicity of Tyr in dogs are required.

Overall, our study demonstrated for the first time that natural compounds can present inhibitory effects on ocular inflammatory response in dogs. Oral Tyr administration significantly prevented ACP-induced BAB breakdown with a similar potency to that exhibited by carprofen, which may be used to prevent and reduce inflammatory responses in veterinary ophthalmology. These findings indicated that Tyr may be useful for the management of anterior uveitis associated with surgical procedures, including intraocular surgery, in dogs.

\section{REFERENCES}

1. Babu, K. and Mahendradas, P. 2013. Medical management of uveitis - current trends. Indian J. Ophthalmol. 61: 277-283. [Medline] [CrossRef]

2. Bertelli, A. A., Migliori, M., Panichi, V., Longoni, B., Origlia, N., Ferretti, A., Cuttano, M. G. and Giovannini, L. 2002. Oxidative stress and inflammatory reaction modulation by white wine. Ann. N. Y. Acad. Sci. 957: 295-301. [Medline] [CrossRef]

3. Biswas, J., Annamalai, R. and Islam, M. 2017. Update on clinical characteristics and management of uveitic macular edema. Kerala J. Ophthalmol. 29: 4-8. [CrossRef]

4. Brightman, A. H. 2nd., Helper, L. C. and Hoffman, W. E. 1981. Effect of aspirin on aqueous protein values in the dog. J. Am. Vet. Med. Assoc. 178: 572-573. [Medline]

5. Bu, Y., Rho, S., Kim, J., Kim, M. Y., Lee, D. H., Kim, S. Y., Choi, H. and Kim, H. 2007. Neuroprotective effect of tyrosol on transient focal cerebral ischemia in rats. Neurosci. Lett. 414: 218-221. [Medline] [CrossRef]

6. Chandramohan, R., Pari, L., Rathinam, A. and Sheikh, B. A. 2015. Tyrosol, a phenolic compound, ameliorates hyperglycemia by regulating key enzymes of carbohydrate metabolism in streptozotocin induced diabetic rats. Chem. Biol. Interact. 229: 44-54. [Medline] [CrossRef]

7. Chen, X., Gallar, J. and Belmonte, C. 1997. Reduction by antiinflammatory drugs of the response of corneal sensory nerve fibers to chemical irritation. Invest. Ophthalmol. Vis. Sci. 38: 1944-1953. [Medline]

8. Cunha-Vaz, J. 1979. The blood-ocular barriers. Surv. Ophthalmol. 23: 279-296. [Medline] [CrossRef]

9. Durieux, P., Etchepareborde, S., Fritz, D. and Rosolen, S. G. 2015. Tumor necrosis factor-alpha concentration in the aqueous humor of healthy and diseased dogs: a preliminary pilot study. J. Fr. Ophtalmol. 38: 288-294. [Medline] [CrossRef]

10. Eakins, K. E. 1977. Prostaglandin and non-prostaglandin mediated breeakdown of the blood-aqueous barrier. Exp. Eye Res. 25 Suppl: $483-498$. [Medline] [CrossRef]

11. Giuliano, E. A. 2004. Nonsteroidal anti-inflammatory drugs in veterinary ophthalmology. Vet. Clin. North Am. Small Anim. Pract. 34: 707-723. [Medline] [CrossRef]

12. Hashim, Y. Z., Rowland, I. R., McGlynn, H., Servili, M., Selvaggini, R., Taticchi, A., Esposto, S., Montedoro, G., Kaisalo, L., Wähälä, K. and Gill, C. I. 2008. Inhibitory effects of olive oil phenolics on invasion in human colon adenocarcinoma cells in vitro. Int. J. Cancer 122: 495-500. [Medline] [CrossRef]

13. Holmberg, B. J. and Maggs, D. J. 2004. The use of corticosteroids to treat ocular inflammation. Vet. Clin. North Am. Small Anim. Pract. 34: 693-705. [Medline] [CrossRef]

14. Källberg, M. E., Brooks, D. E., Gelatt, K. N., Garcia-Sanchez, G. A., Szabo, N. J. and Lambrou, G. N. 2007. Endothelin-1, nitric oxide, and glutamate in the normal and glaucomatous dog eye. Vet. Ophthalmol. 10 Suppl 1: 46-52. [Medline] [CrossRef]

15. Kanai, K., Nagata, S., Hatta, T., Sugiura, Y., Sato, K., Yamashita, Y., Kimura, Y. and Itoh, N. 2016. Therapeutic anti-inflammatory effects of luteolin on endotoxin-induced uveitis in Lewis rats. J. Vet. Med. Sci. 78: 1381-1384. [Medline] [CrossRef]

16. Krohne, S. G. 1994. Effect of topically applied 2\% pilocarpine and $0.25 \%$ demecarium bromide on blood-aqueous barrier permeability in dogs. Am. J. Vet. Res. 55: 1729-1733. [Medline]

17. Li, M., Chen, X., Liu, J., Wang, D., Gan, L., Lv, X. and Qiao, Y. 2016. Treatment of experimental autoimmune uveoretinitis with different natural compounds. Mol. Med. Rep. 13: 4654-4658. [Medline] [CrossRef]

18. Millichamp, N. J., Dziezyc, J., Rohde, B. H., Chiou, G. C. and Smith, W. B. 1991. Acute effects of anti-inflammatory drugs on neodymium:yttrium aluminum garnet laser-induced uveitis in dogs. Am. J. Vet. Res. 52: 1279-1284. [Medline]

19. Mustafa, M., Muthusamy, P., Hussain, S. S., Shimmi, S. and Sein, M. 2014. Uveitis: pathogenesis, clinical presentations and treatment. IOSR J. Pharm. 4: 42-47.

20. Pinard, C. L., Gauvin, D., Moreau, M., Martel-Pelletier, J., Pelletier, J. P. and Troncy, E. 2011. Measurements of canine aqueous humor inflammatory mediators and the effect of carprofen following anterior chamber paracentesis. Vet. Ophthalmol. 14: 296-303. [Medline] [CrossRef]

21. Rankin, A. J., Khrone, S. G. and Stiles, J. 2011. Evaluation of four drugs for inhibition of paracentesis-induced blood-aqueous humor barrier 
breakdown in cats. Am. J. Vet. Res. 72: 826-832. [Medline] [CrossRef]

22. Rankin, A. J., Sebbag, L., Bello, N. M., Crumley, W. R. and Allbaugh, R. A. 2013. Effects of oral administration of anti-inflammatory medications on inhibition of paracentesis-induced blood-aqueous barrier breakdown in clinically normal cats. Am. J. Vet. Res. 74: 262-267. [Medline] [CrossRef]

23. Renzo, R., Ribeiro, A. P., da Silva, M. L., da Silva, G. A., Ortencio, K. P., Barros Sobrinho, A. A., Mineo, T. W. and Laus, J. L. 2014. Intraocular pressure, specular microscopy, and prostaglandin E2 concentration in dogs with mature and hypermature cataract. Vet. Ophthalmol. 17: $280-285$. [Medline] [CrossRef]

24. Rothova, A., Suttorp-van Schulten, M. S., Frits Treffers, W. and Kijlstra, A. 1996. Causes and frequency of blindness in patients with intraocular inflammatory disease. Br. J. Ophthalmol. 80: 332-336. [Medline] [CrossRef]

25. Roze, M., Thomas, E. and Davot, J. L. 1996. Tolfenamic acid in the control of ocular inflammation in the dog: pharmacokinetics and clinical results obtained in an experimental model. J. Small Anim. Pract. 37: 371-375. [Medline] [CrossRef]

26. Samuel, S. M., Thirunavukkarasu, M., Penumathsa, S. V., Paul, D. and Maulik, N. 2008. Akt/FOXO3a/SIRT1-mediated cardioprotection by n-tyrosol against ischemic stress in rat in vivo model of myocardial infarction: switching gears toward survival and longevity. J. Agric. Food Chem. 56: 9692-9698. [Medline] [CrossRef]

27. Saratikov, A. S. and Krasnov, E. A. 2004. Rhodiola Rosea (Golden root): A Valuable Medicinal Plant. pp. 1-205. Tomsk University Press, Tomsk.

28. Sato, K., Mihara, Y., Kanai, K., Yamashita, Y., Kimura, Y. and Itoh, N. 2016. Relative potency of tyrosol in the treatment of endotoxin-induced uveitis in rats. J. Vet. Med. Sci. 78: 1631-1634. [Medline] [CrossRef]

29. Sato, K., Mihara, Y., Kanai, K., Yamashita, Y., Kimura, Y. and Itoh, N. 2016. Tyrosol ameliorates lipopolysaccharide-induced ocular inflammation in rats via inhibition of nuclear factor (NF)-kB activation. J. Vet. Med. Sci. 78: 1429-1438. [Medline] [CrossRef]

30. Tjebbes, G. W., van Delft, J. L., Barthen, E. R. and van Haeringen, N. J. 1990. d-Ibuprofen in ocular inflammation induced by paracentesis of the rabbit eye. Prostaglandins 40: 29-33. [Medline] [CrossRef]

31. van der Woerdt, A. 2001. Management of intraocular inflammatory disease. Clin. Tech. Small Anim. Pract. 16: 58-61. [Medline] [CrossRef]

32. Ward, D. A., Ferguson, D. C., Kaswan, R. L. and Green, K. 1992. Leukotrienes and sensory innervation in blood-aqueous barrier disruption in the dog. J. Ocul. Pharmacol. 8: 69-76. [Medline] [CrossRef]

33. Ward, D. A., Ferguson, D. C., Ward, S. L., Green, K. and Kaswan, R. L. 1992. Comparison of the blood-aqueous barrier stabilizing effects of steroidal and nonsteroidal anti-inflammatory agents in the dog. Prog. Vet. Comp. Ophthalmol. 2: 117-124. 